\title{
Malignant melanoma of soft parts with osteoclast-rich giant cells: A rare tumour of the jejunum
}

\author{
Saumyaranjan Mallick ${ }^{1}$, Lavleen Singh ${ }^{1}$, Kartik Rajan², Meher Chand Sharma ${ }^{1}$, VK Bansl2 ${ }^{2}$, \\ Amit K Dinda ${ }^{1}$ \\ 1. Department of Pathology, All India Institute of Medical Sciences, New Delhi, India \\ 2. Department of Surgery, All India Institute of Medical Sciences, New Delhi, India
}

\section{CASE REPORT}

Please cite this paper as: Mallick S, Singh L, Rajan K, Sharma, MC, Bansl VK, Dinda AK. Malignant melanoma of soft parts with osteoclast-rich giant cells: A rare tumour of the jejunum. AMJ 2014, 7, 4, 181-184. http://doi.org/10.21767/AMJ.2014.1970

Corresponding Author:

Amit Kumar Dinda

All India Institute of Medical Sciences, Department of Pathology, Room No 1050, Ansari Nagar, New Delhi110029

Email: amit_dinda@yahoo.com

\section{ABSTRACT}

Malignant melanoma of soft parts (MMSP), first described by Franz M. Enzinger, is a rare tumour of unknown cell origin. We describe a case of a 45-year-old male who presented with a one-year history of abdominal pain, weakness, and anaemia. Computerised tomography enteroclysis showed a mass in the jejunum that was suggestive of a gastrointestinal stromal tumour. An ulceroinfiltrative lesion measuring $6.5 \times 4 \times 2 \mathrm{~cm}$ was identified. Microscopy revealed typical features of MMSP with numerous osteoclasts-like giant cells. The diverse histomorphology and immunohistochemical characteristics of this case involving a rare tumour at a rare site is presented.

\section{Key Words}

Malignant melanoma of soft parts, jejunum, osteoclastic giant cells.

\section{What this study adds:}

\section{What is known about this subject?}

Malignant melanoma of soft parts (MMSP) is a rare soft tissue neoplasm that occurs mostly in the extremities. Gastrointestinal MMSP is extremely rare.

\section{What is the key finding of this report?}

Our case is being presented due to its rarity and histomorphological differentiation, which must be recognised to differentiate it from GIST and poorly differentiated carcinomas. Due to the high risk of recurrence and distal metastasis, a close follow-up and screening of the patient is necessary.

\section{What are the implications for future practice?}

The most common mesenchymal tumour of the small intestine is a gastrointestinal stromal tumour(GIST). MMSP in this location is very rare, and this case of osteoclastic-giant cell rich MMSP is also extremely rare. Other more common tumours like leiomyosarcoma, epitheloid GIST, and malignant peripheral nerve sheath tumour should be considered as differential diagnoses.

\section{Background}

Malignant melanoma of soft parts (MMSP) or the clear cell sarcoma (CCS) is a rare tumour of unknown cell origin, and was first described by Franz M. Enzinger. ${ }^{1,2}$ The tumours are usually found around tendons or aponeuroses in the extremities. Only a few cases have been described in intra-abdominal organs. Ekfors et al. first reported the occurrence of MMSP in the gastrointestinal tract. ${ }^{3}$ Age and sex distribution remain unknown due to the rarity of this lesion. Microscopically it mimics the epitheloid variant of gastrointestinal stromal tumour (GIST). The histogenesis of the tumour is poorly understood. Only finger countable cases have been reported in the literature. The characteristic cytogenetic finding of MMSP is translocation $t(12 ; 22)$ (q13; q12), which helps in differentiating these tumours from close mimickers. ${ }^{4}$ Here we describe a case MMSP of the jejunum with numerous osteoclast-rich giant cells.

\section{Case details}

A 45-year-old male presented with a one-year history of a painful abdomen, weakness, and easy fatigability. There was no history of haematemesis, malena, jaundice, abdominal distention, vomiting, or fever. No evidence of 
recurrent infection was found. On general physical examination, there was pallor. Previous medical history was unremarkable. Haemogram revealed haemoglobin of $50 \mathrm{~g} / \mathrm{L}$ (reference; 120-140g/L). Abdominal examination did not reveal any organomegaly or palpable lump. An abdominopelvic ultrasonogram, upper gastrointestinal endoscopy, and colonoscopy were within normal limits. Enteroscopy showed a large ulcerated growth seen at the mid-jejunum. Computerised tomography enteroclysis showed long segment aneurismal dilatation of the jejunum with thick enhancing mass and enlarged mesenteric lymph nodes. The provisional diagnosis of a lymphoma or GIST was made.

Diagnostic laparoscopy showed no ascites, peritoneal, and omental deposits, or liver metastasis. A mass was seen at midjejunum involving the mesentery. Intra-operatively the mass was present in the jejunum; $60 \mathrm{~cm}$ distal to the duodenojejunal junction, and extended up to the root of mesentery. Following serial ligation of the mesenteric vessels, resection of the involved jejunum with the mass was done with proximal $10 \mathrm{~cm}$ and distal $5 \mathrm{~cm}$ margin.

Pathological features: Grossly, a $4.4 \times 4.3 \mathrm{~cm}$, solid, poorly circumscribed tumour was seen which appeared to infiltrate transmurally along with ulceration of the overlying mucosa. On cut section, the tumour showed grey to yellow gelatinous areas and haemorrhage (Figures $1 \mathrm{a}$ and $1 \mathrm{~b}$ ).

Figure 1: (a) Gross photograph shows a growth mainly in serosa; (b) Cut surface shows an ulceroproliferative growth with transmural infiltration

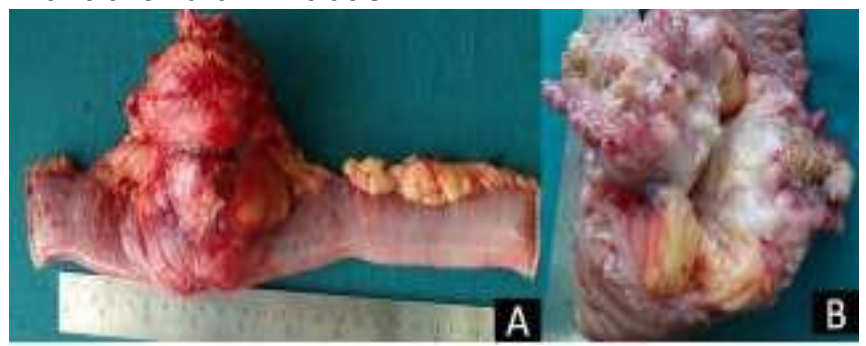

Haematoxylin and eosin (H\&E) stained tissue sections from the mass showed a normal jejunal mucosa with tumour in the submucosa. Tumuor cells were arranged in lobules/nests separated by fibrovascular septae. Individual tumour cells were round with a moderate amount of cytoplasm, large vesicular nuclei with prominent nucleoli in a few of them. Nuclear pleomorphism with sparse mitotic figures were seen. Numerous osteoclast-like multinucleated giant cells were noted scattered in between the tumour cells (Figures $2 a, 2 b$, and $2 \mathrm{c}$ ). Immunohistochemically the tumour cells and the giant cells showed diffuse positivity for S-100 (Dako). All other markers such as pan cytokeratin, CD20, CD3, epithelial membrane antigen, smooth muscle actin, CD68, chromogranin, synaptophysin, CD117, DOG1, and HMB45 were negative (Figure 3).

Figure 2 (a, b): Microphotograph showing normal jejunal mucosa with tumour in the submucosa; Tumour cells arranged in lobules/nests separated by fibrovascular septae (H\&Ex40, x100); (c) Individual tumour cells: Round with moderate amount of cytoplasm and large vesicular nuclei, Prominent nucleoli in a few cells. Numerous multinucleated giant cells (H\&Ex200); (d) Scanning electron microscopy showing premelanosomes (arrow)

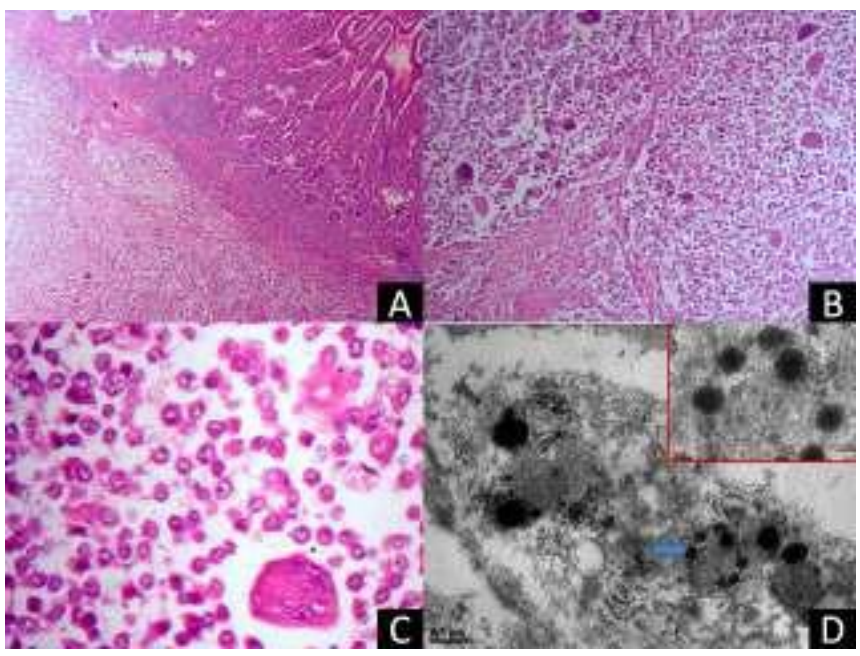

Figure 3: Microphotograph of immunohistochemistry showing positive for $S-100(K)$ and negative for the rest of the markers. (a) Pan cytokeratin (x100); (b) CD20 (x100); (c) CD3 (x100); (d) epithelial membrane antigen (x100); (e) smooth muscle actin (x100); (f) CD68 (x100); (g) chromogranin (x100); (h) synaptophysin (x100); (i) CD117 (x100); (j) Dog1 (x100); (k) S100 (x100); and (l) HMB45 (x100)

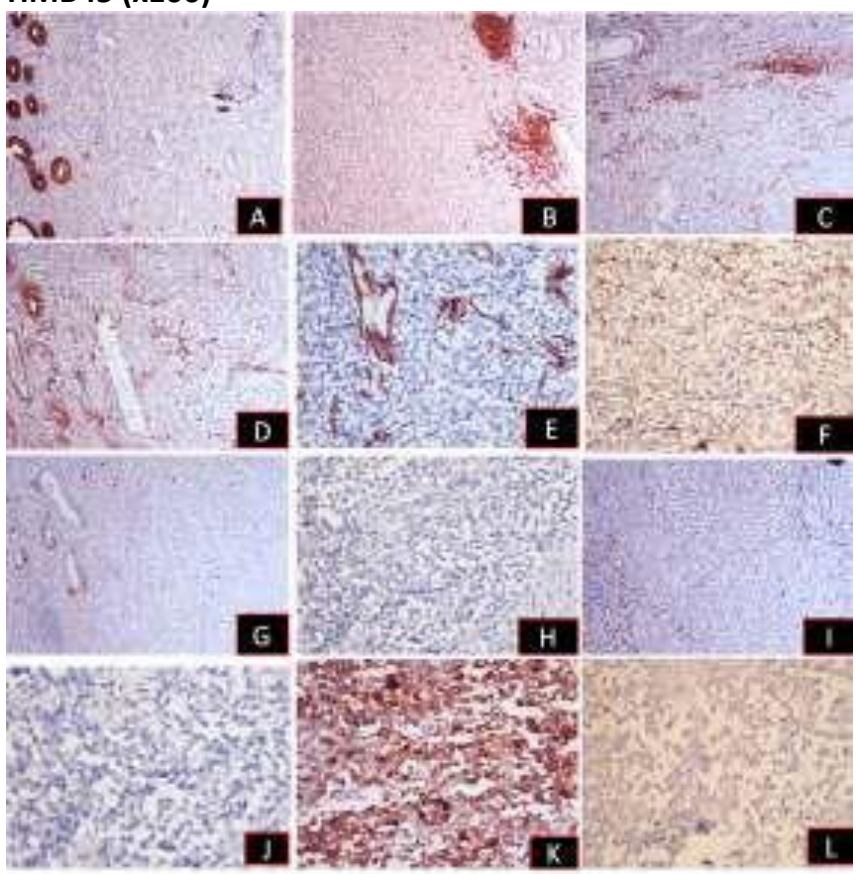




\section{Discussion}

Mesenchymal tumours comprise a very significant proportion of small intestinal malignancies, accounting for 14 per cent of all cases, the majority of which are GISTs and leomyosarcomas. ${ }^{5}$ Ekfors et al., in 1993, were the first to report the occurrence of MMSP in the duodenum. ${ }^{3}$ The rarity of this tumour can be judged by the fact that since then only 30 cases have been reported, of which Zambrano et al. described the largest series comprising six cases. ${ }^{6}$

The exact histogenesis of the tumour is not known. On the basis of morphology, Enzinger first termed it as clear cell sarcoma of the tendon sheath and aponeuroses. ${ }^{1}$ Later on, due to the ultra-structural demonstration of premelanosome in these cells by Hoffman et al., Enzinger renamed the tumour as malignant melanoma of soft parts (MMSP). ${ }^{1,7}$ They argued that the tumour cells also resembled melanoma or a nevus cell. The tumour is most commonly seen in the upper and lower extremities, with a few cases reported in the face. Gastrointestinal occurrences are very rare. The ileum is the most common site; other reported sites include the stomach, colon, and duodenum. ${ }^{8,9}$

In contrast to tumours in the soft parts, tumours in the gastrointestinal tract show both morphological and cytogenetic variations. Although the first morphological variation of the presence of numerous giant cells was noted by Alper and Beckwith, the entity osteoclast-rich giant cell tumour was first described later by Zambrano et al. in 2003 .

${ }^{10}$ The most common cytogenetic abnormality is $t(12 ; 22)$ (q13; q12) translocation, which causes the fusion of EWSR1ATF1 genes. Four types of fusion transcripts have been identified, of which fusions between exon 8 of EWSR1 and exon 4 of ATF1 is the most common. Another variant of fusion of EWSR1-CREB secondary to translocation $t$ (2:22) was demonstrated by Antonescu et al. ${ }^{11,12}$

Recently, the MMSP of the gastrointestinal tract has been divided into four categories: ${ }^{13}$

1) Small bowel tumours that are identical to MMSP in all morphological and immunohistochemical aspects (S-100, HMB45, and or all other melanocytic marker), $t$ (11:22) translocation resulting EWS-ATF1 fusion gene.

2) Tumours identical to the above but which lack the melanocytic marker.

3) Tumours similar to those in category 2 that feature a scattering of osteoclast-like multinucleated giantcells.

4) Tumors resembling cutaneous melanomas but with a genetic signature of MMSP.

Our case belongs to category 3. However, later Kosemehmetoglu et al. morphologically classified MMSP into two groups: gastrointestinal stromal tumours (CCSLGT), which contain the osteoclast-like cell, and soft tissue type CCS without giant cells. ${ }^{14}$

Although the tumours most commonly occur in the third to fifth decade of life, a single case in a child (10 years old) has also been reported. ${ }^{9,15}$ Its erstwhile name-"clear cell sarcoma" -is due to the typical histological findings of large cells with clear cytoplasm and prominent nucleoli. The tumour shows an organoid and trabecular pattern of arrangement. Unlike soft tissue CCS, the tumours of gastrointestinal tract shows brisk mitosis and necrosis.

Histologically, the closest differential diagnosis is malignant giant cell tumours, leiomyosarcoma, GIST containing osteoclast-like multinucleated giant cells, and, less commonly, malignant peripheral nerve sheath tumours and PEComas. S-100 positivity, the absence of all other immunohistochemical markers, and the presence of giant cells aid in the diagnosis. No marker can differentiate MMSP from malignant melanoma; the confirmation of diagnosis can only be done by cytogenetic studies.

The intestinal MMSPs show a more aggressive course than their soft tissue counterparts. Most of the cases had lymph node metastases, as was seen in our case. The most common site of metastasis in intestinal MMSPs was the liver, in contrast with soft tissue MMSP, which showed a predilection for lung metastasis. ${ }^{14}$ The difference is probably due to vascular drainage. The literature shows that liver metastasis occurred in most of the cases in the later course of the disease. The exact prognostic factor is not known due to the limited number of cases. A tumour size $>5 \mathrm{~cm}$, and necrosis irrespective of tumour size are thought to be poor prognostic factors. ${ }^{15}$ As reviewed by Kosemehmetoglu et al., all 12 patients with osteoclast-rich tumours died due to visceral metastasis in less than 36 months; in comparison, the clear cell sarcoma of soft parts had better prognosis of five-year survival of 54 per cent. ${ }^{14,16}$ Complete excision of these tumours is the mainstay treatment, along with radiotherapy. The role of chemotherapy is not known.

\section{Conclusion}

Our case is being presented due to its rarity and histomorphological differentiation, which must be recognised to differentiate it from GIST and poorly differentiated carcinomas. Due to high risk of recurrence and distal metastasis, a close follow-up and ongoing screening of the patient is necessary 


\section{References}

1. Chung EB, Enzinger FM. Malignant melanoma of soft parts. A reassessment of clear cell sarcoma. Am J Surg Pathol. 1983;7:405-13.

2. Enzinger FM. Clear-cell sarcoma of tendons and aponeuroses. an analysis of 21 cases. Cancer. 1965;18:1163-74.

3. Ekfors TO, Kujari $H$, Isomäki $M$. Clear cell sarcoma of tendons and aponeuroses (malignant melanoma of soft parts) in the duodenum: the first visceral case. Histopathology. 1993;22:255-9.4

4. Langezaal SM, Graadt van Roggen JF, Cleton-Jansen AM, Baelde JJ, HogendoornPC. Malignant melanoma is genetically distinct from clear cell sarcoma of tendons and aponeurosis (malignant melanoma of soft parts). $\mathrm{Br} \mathrm{J}$ Cancer. 2001;84:535-8.

5. Thomas RM, Sobin LH. Gastrointestinal cancer. Cancer 1995;75:154-70.

6. Zambrano E, Reyes-Mugica M, Franchi A, Rosai J. An osteoclast-rich tumor of the gastrointestinal tract with features resembling clear cell sarcoma of soft parts: reports of 6 cases of a GIST simulator. Int J Surg Pathol. 2003;11:75-81.

7. Hoffman GJ, Carter D. Clear cell sarcoma of tendons and aponeuroses with melanin. Arch Pathol. 1973;95:22-5.

8. D'Amico FE, Ruffolo C, Romeo S, Massani M, Dei Tos AP, Bassi N. Clear cell sarcoma of the ileum: report of a case and review of the literature. Int J Surg Pathol. 2012;20:401-6.

9. Lagmay JP, Ranalli M, Arcila M, Baker P. Clear cell sarcoma of the stomach. Pediatr Blood Cancer. 2009;53:214-6.

10. Alpers CE, Beckstead JH. Malignant neuroendocrine tumor of the jejunum with osteoclast-like giant cells. Enzyme histochemistry distinguishes tumor cells from giant cells. Am J Surg Pathol. 1985;9:57-64.

11. Wang WL, Mayordomo E, Zhang W, Hernandez VS, Tuvin D, Garcia L, Lev DC, Lazar AJ, López-Terrada D. Detection and characterization of EWSR1/ATF1 and EWSR1/CREB1 chimeric transcripts in clear cell sarcoma (melanoma of soft parts). Mod Pathol. 2009;22:1201-9.

12. Antonescu CR, Nafa K, Segal NH, Dal Cin P, Ladanyi M. EWS-CREB1: a recurrent variant fusion in clear cell sarcoma--association with gastrointestinal location and absence of melanocytic differentiation. Clin Cancer Res. 2006 15;12:5356-62.

13. Rosai J. 2011:Rosai and Ackerman's Surgical Pathology (volume 1) 10th Edition. New York: Mosby; pp395-96

14. Kosemehmetoglu K, Folpe AL. Clear cell sarcoma of tendons and aponeuroses, and osteoclast-rich tumour of the gastrointestinal tract with features resembling clear cell sarcoma of soft parts: a review and update. J Clin Pathol. 2010;63:416-23.

15. Lucas DR, Nascimento AG, Sim FH. Clear cell sarcoma of soft tissues. Mayo Clinic experience with 35 cases. Am J Surg Pathol. 1992;16:1197-204.

16. Deenik W, Mooi WJ, Rutgers EJ, Peterse JL, Hart AA, Kroon BB. Clear cell sarcoma (malignant melanoma) of soft parts: A clinicopathologic study of 30 cases. Cancer. 1999 Sep 15;86(6):969-75.

\section{PEER REVIEW}

Not commissioned. Externally peer reviewed.

\section{CONFLICTS OF INTEREST}

The authors declare that they have no competing interests.

\section{PATIENT CONSENT}

The authors Mallick S, Singh L, Ranjan K, Sharma MC, BansI VK, Dinda AK, declare that:

1. They have obtained written, informed consent for the publication of the details relating to the patient(s) in this report.

2. All possible steps have been taken to safeguard the identity of the patient(s).

3. This submission is compliant with the requirements of local research ethics committees. 